\title{
Long-term Results of Two Different Surgical Techniques Used in Carpal Tunnel Syndrome
}

\author{
Serdar Ercan ${ }^{1, \odot ~ Z e k i ~ S e r d a r ~ A t a i z i ~}{ }^{2}$ \\ ${ }^{1}$ Department of Neurosurgery, Eskisehir City Hospital, Eskisehir, \\ Turkey \\ ${ }^{2}$ Department of Neurosurgery, Yunus Emre State Hospital, Eskisehir, \\ Turkey \\ Indian J Neurosurg 2021;1:65-68.
}

\begin{abstract}
Address for correspondence Serdar Ercan, MD, Department of Neurosurgery, Eskisehir City Hospital, 71 Evler Mah, Odunpazari, Eskisehir 26020 Turkey (e-mail: srdrercn@gmail.com).
\end{abstract}

\begin{abstract}
Objective Carpal tunnel syndrome (CTS), the compression of the median nerve under the carpal ligament, is the most common peripheral nerve entrapment of the upper extremity. While conservative treatment is used for patients with mild and moderate symptoms, surgical treatment is preferred for severe symptoms. The aim of the study is to evaluate the difference between transverse and longitudinal incision by comparing postoperative pain and recurrence rates.

Methods The patients were divided into two groups according to the surgical incision type. Surgical intervention was applied to patients in group T (transverse incision) and group $L$ (longitudinal incision) by the same two surgeons in each group. All patients were followed-up with electromyography (EMG) and performance scale before and after surgical treatment. If the postoperative EMG result was similar to the preoperative EMG result, it was accepted as recurrent CTS.

Keywords

- peripheral nerve

- carpal tunnel

- entrapment

- surgical approach

- recurrence

Results A total of 418 patients were included to the study. Six patients in the group $T$ with transverse incision, and 18 patients in the group $L$ with longitudinal incision, were reoperated for an average of $6 \pm 2$ months after the primary surgery.

Conclusion Complications are less, and recurrent nerve compression is less in longitudinal approach, since surgical intervention is performed by seeing the median nerve directly.
\end{abstract}

\section{Introduction}

Carpal tunnel syndrome (CTS) is the most common nerve entrapment among all peripheral neuropathies. The compression of median nerve occurs while the nerve courses through the carpal tunnel. During the course of the median nerve through the carpal tunnel, compression of the nerve develops as a result of its compression. The carpal tunnel is an oval-shaped canal extending from the wrist line to the middle of the palm on the wrist volar face. It is adjacent to the hamate, triquetrum and pisiform bone on the ulnar side, with trapezium, scaphoid and flexor carpi radialis retinaculum on the radial side, with the metacarpal base at the dorsal and the transverse carpal ligament, which is 3 to $4 \mathrm{~cm}$ in length and 1 to $3 \mathrm{~mm}$ in the anterior.

It often causes painful paresthesia and atrophy in patients. The pain is generally severe and wake the patients up while sleeping. It is observed in the community at the rate of 0.6 to $3.4 \% .^{1,2}$

It is more common in women. ${ }^{3}$ Obesity, hypothyroidism, diabetes mellitus, pregnancy, kidney disease, inflammatory arthritis, acromegaly, mucopolysaccharidosis, lifestyle, mode of work, and advanced age are observed in etiology. ${ }^{4}$
DOI https://doi.org/ $10.1055 / \mathrm{s}-0041-1725209$ ISSN 2277-954X. (c) 2021. Neurological Surgeons' Society of India.

This is an open access article published by Thieme under the terms of the Creative Commons Attribution-NonDerivative-NonCommercial-License, permitting copying and reproduction so long as the original work is given appropriate credit. Contents may not be used for commercial purposes, or adapted, remixed, transformed or built upon. (https://creativecommons.org/licenses/by-nc-nd/4.0/). Thieme Medical and Scientific Publishers Pvt. Ltd. A-12, 2nd Floor, Sector 2, Noida-201301 UP, India 
The diagnosis is made by clinical history of the CTS patient, physical and neurological examination, and measurement of electromyographic (EMG) nerve conduction velocity. The Tinel, Phalen, and Durkan tests, which are designed to diagnose the nerve entrapment by manual compression on the carpal tunnel, were applied during the physical examination. ${ }^{5}$

The treatment model is determined according to the compression of the median nerve and the severity of the clinical findings. In the presence of mild and moderate symptoms, medical treatment is administered primarily. Surgery is preferred in moderate-to-severe cases or when conservative treatment fails. The literature has defined median nerve decompression surgery in two ways: transverse and longitudinal in the treatment of CTS. ${ }^{6,7}$

Our aim is to evaluate the difference between transverse and longitudinal incision by comparing postoperative pain and recurrence rates and to reveal the differences.

\section{Materials and Methods}

Patients who were admitted to hospital between 2016 to 2019 with symptoms of CTS were examined with physical evaluation and EMG. Patients with moderate and severe median nerve entrapment neuropathy symptoms were included in the study and treated with surgical intervention. Patients who underwent a previous surgical treatment, bone fracture, blunt and sharp trauma at wrist were excluded. The patients were divided into two groups as transverse (group T) and longitudinal (group L) groups, according to the surgical incision type. Surgical intervention was applied to patients in group $\mathrm{T}$ and group $\mathrm{L}$ by the same two surgeons in each group. All patients were followed-up with EMG and performance scale before and after surgical treatment. Patients were followed-up for an average of 12 months. In the event of symptoms similar to the preoperative period, control EMG was taken. If the postoperative EMG result was similar to the preoperative EMG result, it was accepted as recurrent CTS.

Surgical technique: In both surgical techniques, the intervention was performed under local anesthesia (lidocaine, $10 \mathrm{~mL}$ ) without using a tourniquet. The transverse incision was performed from $1 \mathrm{~cm}$ proximal to the skin folded level, parallel to the palmaris longus tendon in the transverse direction, according to the anatomical position of the hand, and positioned approximately 30 degrees dorsiflexed (-Fig. 1). After the skin incision, palmaris muscle that was lateral to the median nerve was detected. Then, the transverse carpal ligament (TCL) incision was made by protecting with the retractors to prevent median nerve injury, and the carpal tunnel was decompressed. For the longitudinal approach, a 3-cm skin incision was made on the longitudinal line, which was drawn from the ulnar side of the third finger to the wrist, on the palm, and on the carpal canal. After dissection, the TCL was opened vertically, and the median nerve was decompressed (-Fig. 2). Postoperatively, the arm was elevated and a bandage applied to prevent edema in all patients.

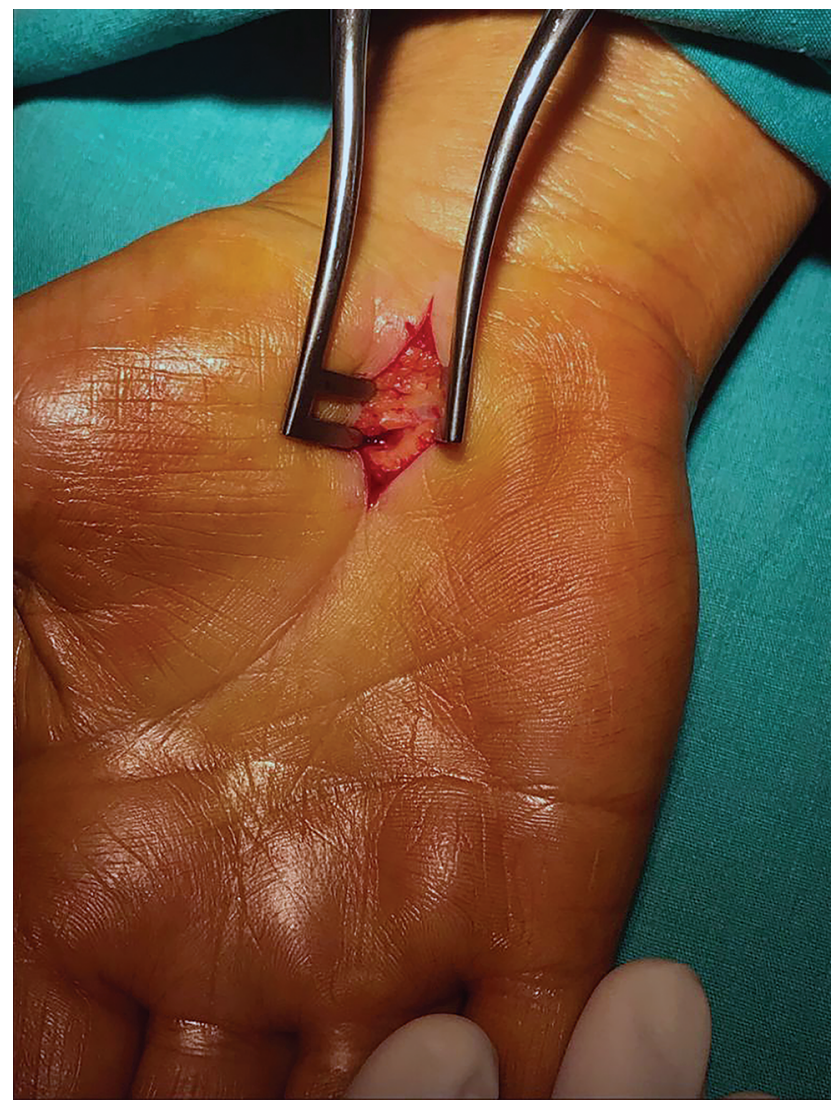

Fig. 1 Incision line for longitudinal approach.

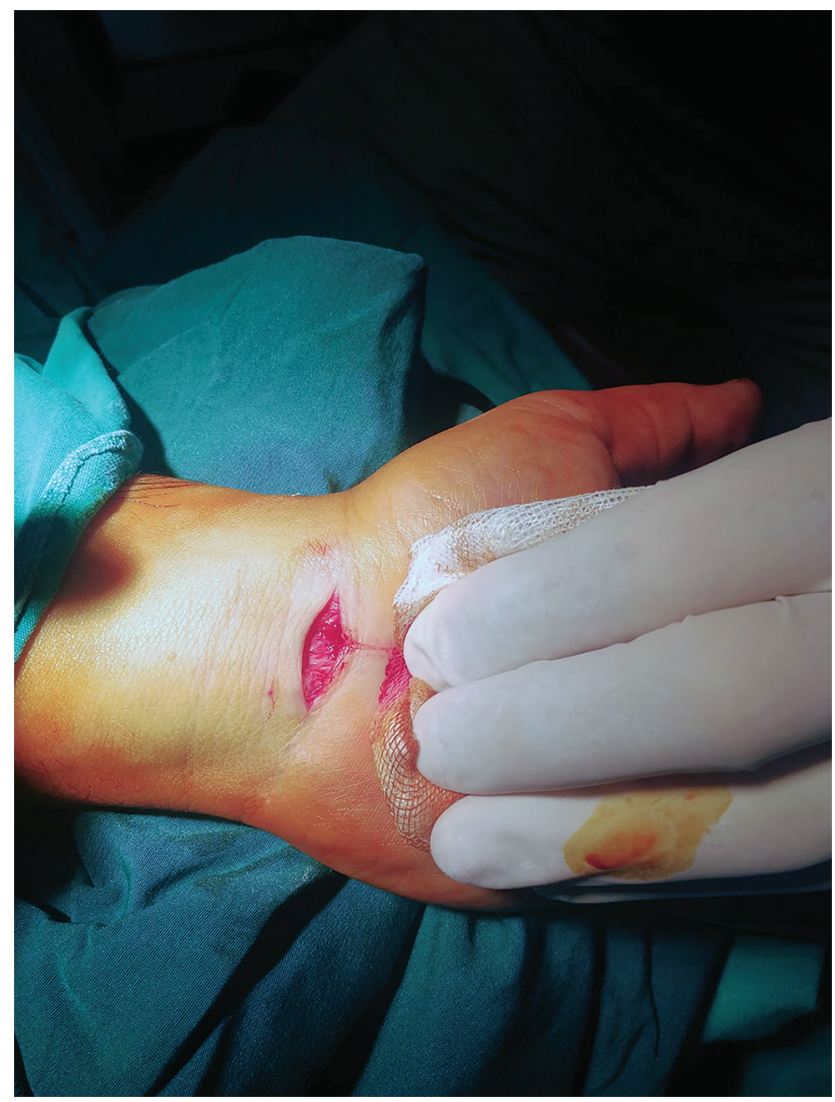

Fig. 2 Incision line for transverse approach. 


\section{Results}

A total of 418 patients were included in the study (group T: 204, group L: 214). In group T, 179 patients underwent unilateral and 25 patients underwent bilateral (total 229 operation) median nerve decompression surgery. The average age of 46 male patients was 57, and 55.4 for 158 female patients. Bilateral decompression surgery was performed in 4 male and 21 female patients. Diabetes in 70 patients ( 16 men and 54 women) and hyperthyroidisms in 12 patients ( 2 men, 10 women) were accompanied. In group L, 214 patients underwent 229 nerve decompression surgery (male: 37 , female: 177 ). A total of 214 patients underwent unilateral and 15 patients underwent bilateral intervention (male: 3 , female: 12 ). The average age was 50 for males and 53.4 for females. A sum of 7 male and 59 female patients were afflicted with diabetes, and 4 male and 16 female patients had thyroid disease. Six patients in group $\mathrm{T}$ with transverse incision, and 18 patients in group $\mathrm{L}$ with longitudinal incision, were reoperated for an average of $6 \pm 2$ months after the primary surgery, due to the fact that the symptoms recurred, and EMG findings expressed recurrent entrapment. The recurrence rate in group $\mathrm{T}$ was found to be significantly higher than group $\mathrm{L}(p<0.005)$. There was no significant difference between the groups in terms of age, gender, and concomitant diseases $(p>0.005)$. While 6 patients sustained nerve damage and 7 sustained deep palmar arc artery damage in group $\mathrm{T}$, neither nerve nor vessel damage was observed in group $\mathrm{L}$. There was no significant difference between the groups in terms of reliable relief and recovery time after the operation.

\section{Discussion}

CTS is the most common peripheral nerve entrapment of the upper extremity, which is frequently encountered by neurology clinicians, neurosurgeons, orthopedic surgeons, and plastic surgeons. The compression of the median nerve under the carpal ligament is the main pathology. The diagnosis is made by history, physical and neurological examination, and EMG measurements. In the treatment of CTS, conservative treatment should be applied primarily for mild and moderate cases. Nonsteroidal anti-inflammatory drugs (NSAIDs), local steroid injection to the wrist, activity limitations with wrist splinting, exercises, and physical therapy are among the options applied. ${ }^{8}$ However, even in mild and moderate nerve entrapment, the success of conservative treatment has been observed to be as low as $22 \% .5,8$

Surgical intervention is preferred in cases that do not respond to conservative treatment and severe entrapment is detected according to EMG results. ${ }^{7}$ The main purpose of surgery is to decompress the carpal tunnel by incising the transverse carpal ligament longitudinally or transversely. The carpal tunnel open surgery technique, defined by Sir James Learmonth in 1933, is still considered the gold standard technique. ${ }^{9}$ It has undergone technical revisions, according to the new approaches applied in surgery. In recent years, the endoscopic applications have become one of the surgical techniques. ${ }^{10}$

Although several different methods have been successfully used to achieve decompression, performing surgery by directly observing the TCL is the basis of treatment. ${ }^{6,7,10}$ There are many previous articles in literature discussing the advantages and disadvantages of these techniques. The release of TCL has been the main form of surgical treatment for CTS over the past few decades and has provided reliable relief and recovery in the vast majority of patients. The incidence of injury is rare, since surgery is performed by observing the nerve directly. ${ }^{11-13}$ We experience that, in transverse incision, insufficient decompression and nerve damage are more common, since the procedure is performed blindly. Thirteen of our patients had nerve and vessel damage during surgery in transverse approach, while no complication occurred in the longitudinal approach.

Patients can relieve symptoms of carpal tunnel well, and most return to daily activities within 6 weeks. Carpal tunnel release with endoscopic and mini-incision technique has an earlier early satisfaction rate than a normal open incision, but we do not observe any difference between the two groups after four months follow up. ${ }^{14}$

In conclusion, symptoms associated with median nerve compression are relieved as a result of decompression by both longitudinal and transverse surgical approaches. However, in

Table 1 Demographic distribution of patients with CTS

\begin{tabular}{|l|l|l|}
\hline & $\begin{array}{l}\text { Group T } \\
\text { (transverse } \\
\text { incision) }\end{array}$ & $\begin{array}{l}\text { Group L } \\
\text { (longitudinal } \\
\text { incision) }\end{array}$ \\
\hline Number of patients $(n)$ & 204 & 214 \\
\hline Sex & 46 & \\
\hline Male & 155 & 37 \\
\hline Female & & 177 \\
\hline Age (mean, y) & 57 & \\
\hline Male & 55.4 & 50 \\
\hline Female & 25 & 53.4 \\
\hline Bilateral decompression & 179 & 15 \\
\hline Unilateral decompression & $2.9 \%$ & 201 \\
\hline Recurrence (\%) & & $8.4 \%$ \\
\hline Contributing disease & 12 & \\
\hline Hypertoroid & 70 & 20 \\
\hline Diabetes & & 66 \\
\hline
\end{tabular}

Abbreviation: CTS, carpal tunnel syndrome. 
contrast to transverse approach, the surgical decompression is performed by seeing the median nerve directly. This direct observation lessens the complication and recurrence of the median nerve entrapment.

\section{Funding}

None.

\section{Conflict of Interest}

None declared.

\section{References}

1 de Krom MC, de Krom CJ, Spaans F. [Carpal tunnel syndrome: diagnosis, treatment, prevention and its relevance to dentistry]. Ned Tijdschr Tandheelkd 2009;116(2):97-101

2 Zyluk A. Is carpal tunnel syndrome an occupational disease? A review. Pol Orthop Traumatol 2013;78:121-126

3 Mondelli M, Giannini F, Giacchi M. Carpal tunnel syndrome incidence in a general population. Neurology 2002;58(2):289-294

4 Gniadek M, Trybus M. [Carpal tunnel syndrome- etiology and treatment]. Przegl Lek 2016;73(7):520-524

5 Teixeira Alves MdeP. Prospective comparative study between proximal transverse incision and the conventional longitudinal incisions for carpal tunnel release. Rev Bras Ortop (English Ed.) 2015;45(5):437-444

6 Mardanpour K, Rahbar M, Mardanpour S. Functional outcomes of 300 carpal tunnel release: $1.5 \mathrm{~cm}$ longitudinal mini-incision. Asian J Neurosurg 2019;14(3):693-697
7 Badger SA, O'Donnell ME, Sherigar JM, Connolly P, Spence RAJ. Open carpal tunnel release-still a safe and effective operation. Ulster Med J 2008;77(1):22-24

8 Carlson H, Colbert A, Frydl J, Arnall E, Elliot M, Carlson N. Current options for nonsurgical management of carpal tunnel syndrome. Int J Clin Rheumatol 2010;5(1):129-142

9 Yoo HM, Lee KS, Kim JS, Kim NG. Surgical treatment of carpal tunnel syndrome through a minimal incision on the distal wrist crease: An anatomical and clinical study. Arch Plast Surg 2015;42(3):327-333

10 Gülşen I, Ak H, Evcılı G, Balbaloglu O, Sösüncü E. A retrospective comparison of conventional versus transverse mini-incision technique for carpal tunnel release. ISRN Neurol 2013;2013:721830

11 Atroshi I, Larsson G-U, Ornstein E, Hofer M, Johnsson R, Ranstam $\mathrm{J}$. Outcomes of endoscopic surgery compared with open surgery for carpal tunnel syndrome among employed patients: randomised controlled trial. BMJ 2006;332(7556):1473

12 Benson LS, Bare AA, Nagle DJ, Harder VS, Williams CS, Visotsky JL. Complications of endoscopic and open carpal tunnel release. Arthroscopy 2006;22(9):919-924, 924.e1-924.e2

13 Jiménez Del Barrio S, Bueno Gracia E, Hidalgo García C, et al. Conservative treatment in patients with mild to moderate carpal tunnel syndrome: a systematic review. Neurologia (English Ed.) 2018;33(9):590-601

14 Aslani HR, Alizadeh K, Eajazi A, et al. Comparison of carpal tunnel release with three different techniques. Clin Neurol Neurosurg 2012;114(7):965-968 